\title{
CAECAL VOLVULUS- A CASE REPORT
}

\author{
Anand Kishore ${ }^{1}$
}

${ }^{1}$ Consultant, Department of General Surgery, RK Life Line Hospital, Sirsa, Haryana, India.

HOW TO CITE THIS ARTICLE: Kishore A. Caecal volvulus- a case report. J. Evolution Med. Dent. Sci. 2018;7(22):2717-2719, DOI: $10.14260 /$ jemds/2018/612

\section{CASE PRESENTATION}

An 18-year-old female presented to surgical emergency with complaints of progressive abdominal distension, vomiting, constipation and fever of 3 days duration. On examination, she was febrile. Abdomen was distended with hyperperistaltic bowel sound and on per rectal examination rectum was empty. Routine blood examinations showed raised total leucocyte count and increased blood urea. X-ray abdomen showed dilated small bowel with multiple fluid level (Figure 1). With the x-ray findings, we made a diagnosis of small bowel obstruction. Initially patient was stabilised, treated conservatively and observed for $12 \mathrm{hrs}$. But she was found to be deteriorating with progressive symptoms of increasing abdominal distension. Patient was planned for emergency exploratory laparotomy as no improvement was seen with a trial of conservative treatment and patient had already reported very late, i.e. after 3 days of duration. On laparotomy we found that distal ileum, caecum, appendix and ascending colon were gangrenous (Figure 2, 3, 4). Hence, we made an intra-op diagnosis of Caecal volvulus. Limited right hemicolectomy was done for gangrenous bowel and double barrel stoma was made as the general condition and nutrition of the patient was poor. Post-operative period was uneventful. Patient was started orally on $5^{\text {th }}$ post-operative day and discharged on 7 th post-operative day. Stoma reversal was done after 3 months.

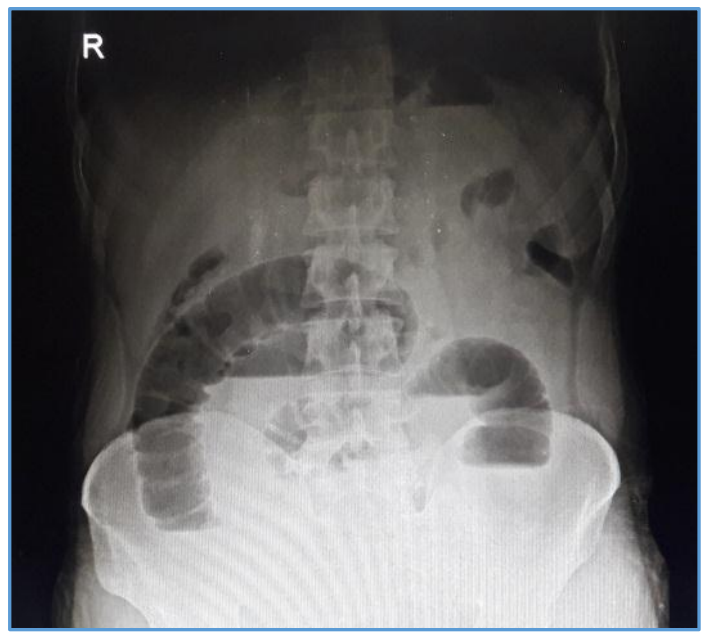

Figure 1. X-Ray Abdomen showing Dilated Small Bowel with Multiple Air Fluid Level

'Financial or Other Competing Interest': None.

Submission 20-04-2018, Peer Review 14-05-2018,

Acceptance 20-05-2018, Published 22-05-2018.

Corresponding Author:

Dr. Anand Kishore,

RK Life Line Hospital,

Sangwan Chowk,

Sirsa-125055, Haryana.

E-mail: anandkishore1980@gmail.com

DOI: $10.14260 /$ jemds $/ 2018 / 612$

\section{(c) (i) $(9$}

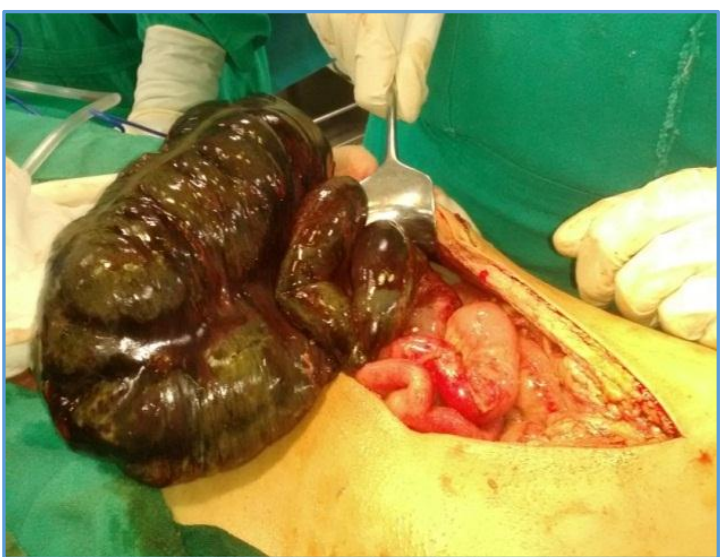

Figure 2. Intraoperative Picture showing Dilated, Grossly Dilated Caecum and Ascending Colon with Gangrene of Bowel

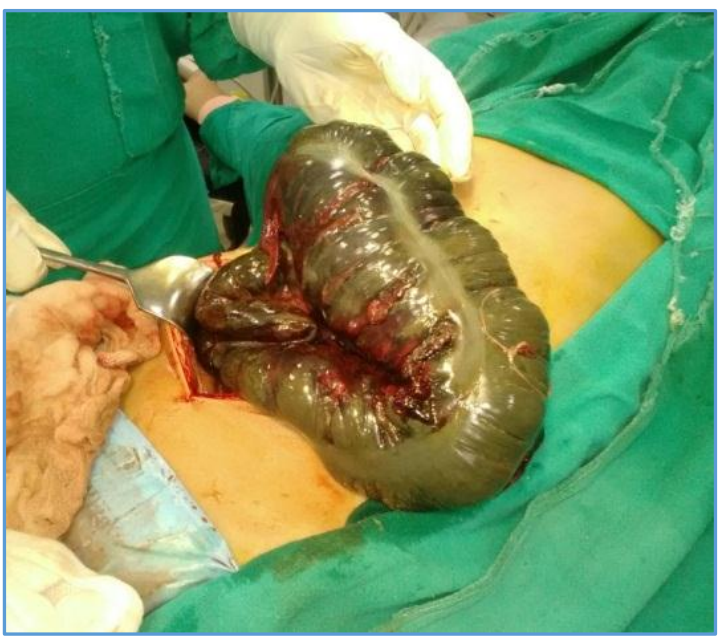

Figure 3. Intraoperative Picture showing Mobile Caecum and Ascending Colon with Gangrene of Bowel. Appendix is also Seen

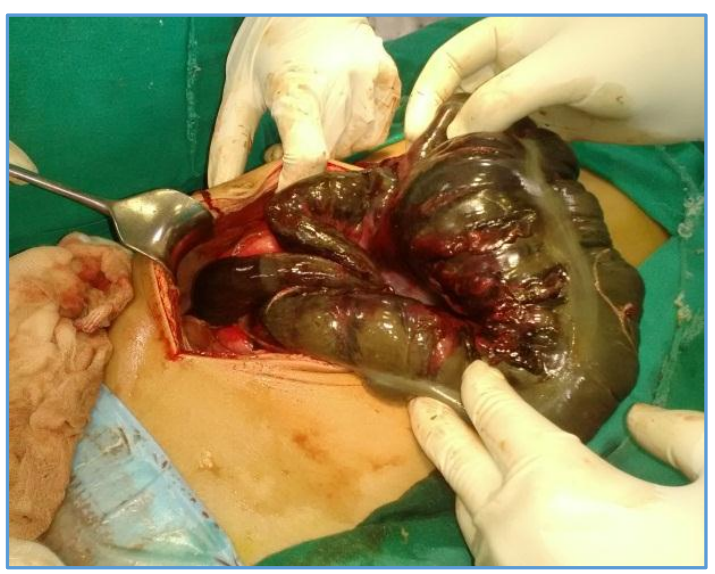

Figure 4. Intraoperative Picture showing the Gangrenous Segment, i.e. Distal Ileum, Appendix, Caecum and Ascending Colon 


\section{DIFFERENTIAL DIAGNOSIS}

Based on symptoms and signs following differential diagnosis were made, intussusception, intestinal perforation, acute colonic pseudo-obstruction (ACPO) Ogilvie syndrome, mesenteric ischaemia, caecal and sigmoid volvulus.

\section{CLINICAL DIAGNOSIS}

Based on clinical examination and radiological findings, a diagnosis of small bowel obstruction was made.

\section{PATHOLOGICAL DISCUSSION}

Colonic volvulus commonly affects sigmoid colon. Caecal volvulus is the second most common to get affected after sigmoid. ${ }^{1}$ Colonic volvulus is an emergency condition where part of the colon twists around its axis due to presence of large, mobile segment of colon with a small mesenteric fixation resulting into partial or complete bowel obstruction with variable degree of compromise of its blood supply. Caecal volvulus is an uncommon clinical condition accounting for less than $2 \%$ of all adult intestinal obstruction. ${ }^{2}$ Caecal volvulus is seen commonly in females and has been reported in all age groups. ${ }^{3}$ Average age of presentation in India is 33 yrs., while in western countries it is 53 yrs. ${ }^{4}$ The aetiology of Caecal volvulus involves axial twisting of the caecum, ascending colon and terminal ileum most commonly in a counter-clockwise fashion. ${ }^{5}$ Patients with incomplete intestinal rotation are prone to develop Caecal volvulus due to inappropriate right colon fixation. Caecal bascule is a variant of Caecal volvulus where an upward and anterior folding of ascending colon occurs ${ }^{5}$ and it constitutes about $10 \%$ of all Caecal volvulus. Caecal bascule and Caecal volvulus have many similar clinical features and both are prone for developing intestinal obstruction and strangulation. Several predisposing factors have been suggested for development of Caecal volvulus. It includes mobile redundant caecum, 6 previous abdominal surgeries where adhesions act as fulcrum in developing rotation, ${ }^{7}$ late term pregnancy, ${ }^{8,9}$ high dietary fibre, 10 adynamic ileus, chronic constipation and distant colonic obstruction.

\section{DISCUSSION OF MANAGEMENT}

The clinical presentation of $\mathrm{CV}$ is highly variable. Broadly three types of clinical presentation is seen ${ }^{11}$ : 1 . Patients with mobile caecum syndrome presents with intermittent pain which is self-limiting and spontaneous resolution occurs; 2 . As acute obstruction associated with severe abdominal pain with vomiting and constipation that does not resolve spontaneously; 3 . As acute fulminant type associated with gangrene of bowel and faecal peritonitis occurs. Physical examination may show asymmetrical abdominal distension with tympanic mass palpable in left upper or mid-abdomen. Blood examinations are not sensitive or specific for CV. ${ }^{5} \mathrm{X}$-ray abdomen is highly sensitive but non-specific for $\mathrm{CV}$, often leading to common diagnosis of small bowel obstruction as seen in our case. No CT scan was done for our patient, as we suspected small bowel obstruction after looking at the x-ray and did not suspect Caecal volvulus. Radiological abnormalities seen in CV on x-ray abdomen are Caecal dilation in $98-100 \%$, single air fluid level in $72-88 \%$, small bowel dilation in $42-55 \%$ and absence of gas in distal colon in $82 \%$ of cases.12 Computed Tomography (CT) is more sensitive and specific than $\mathrm{x}$-rays for diagnosing Caecal volvulus. Radiological signs that help in diagnosis of Caecal volvulus include coffee bean sign where caecum appears in midline and markedly distended, bird beak sign where two ends of volvulised loops are seen converging at the site of torsion, whirl sign where a swirling pattern of mesenteric fat and engorged mesenteric vessel are seen.13 Management of Caecal volvulus include endoscopic decompression, surgical detorsion, caecopexy, caecostomy to right hemicolectomy which may be limited or extensive depending on the length of gangrenous bowel with primary or delayed anastomosis. ${ }^{14}$ Caecopexy has higher recurrence rate, recurrence rate of surgical detorsion may be as high as $40 \% .{ }^{9}$ Right hemicolectomy has an advantage of absolute prevention of recurrence.

\section{FINAL DIAGNOSIS}

Caecal volvulus (CV) is a rare clinical condition causing acute abdominal pain and intestinal obstruction. Patients may present with variable clinical symptoms ranging from intermittent, self-limiting to severe abdominal pain with underlying intestinal strangulation leading to sepsis. In our case report of an 18-year-old female who presented with symptoms and signs of intestinal obstruction. Diagnosis of Caecal volvulus was not suspected in this case. It was only during laparotomy we found patient having gangrenous distal ileum, caecum, appendix and ascending colon and an intraoperative diagnosis of Caecal volvulus was made. The diagnosis of this rare condition needs high index of clinical suspicion in all acute abdomen cases. CT scan is the investigation of choice for Caecal volvulus. Early diagnosis of Caecal volvulus is must to prevent gangrene and faecal peritonitis, which leads to significant morbidity and mortality. Resection of mobile segment or gangrenous segment, i.e. in the form of right hemicolectomy, limited or extensive, is treatment of choice and prevents recurrence.

\section{REFERENCES}

[1] Pousada L. Cecal bascule: an overlooked diagnosis in the elderly. J Am Geriatr Soc 1992;40(1):65-7.

[2] Townsend CM, Beauchamp D, Evers M, et al. Sabiston Textbook of surgery: the biological basis of modern surgical practice. 19th $^{\text {th }}$ edn. Elsevier Saunders 2012: p. 1314-6.

[3] Yeo CJ, Matthews JB, McFadden DW, et al. Shackelford's surgery of the alimentary tract. 7 th edn. New York: Saunders 2012: p. 1851-5.

[4] Gupta S, Gupta SK. Acute caecal volvulus: report of 22 cases and review of literature. Ital J Gastroenterol 1993;25(7):380-4.

[5] Consorti ET, Liu TH. Diagnosis and treatment of caecal volvulus. Postgrad Med J 2005;81(962):772-6.

[6] Wolfer JA, Beaton LE, Anson BJ. Volvulus of the cecum. Anatomical factors in its etiology. Report of a case. Surg Gynecol Obstet 1942;74:882.

[7] Rabinovici R, Simansky DA, Kaplan O, et al. Cecal volvulus. Dis Colon Rectum 1990;33(9):765-9.

[8] Montes H, Wolf J. Cecal volvulus in pregnancy. Am J Gastroenterol 1999;94(9):2554-6. 
[9] Alinovi V, Herzberg FP, Yannopoulos D, et al. Cecal volvulus following cesarean section. Obstet Gynencol 1980;55(1):131-4.

[10] Tejler G, Jiborn H. Volvulus of the cecum. Report of 26 cases and review of the literature. Dis Colon Rectum 1988;31(6):445-9.

[11] Friedman JD, Odland MD, Bubrick MP. Experience with colonic volvulus. Dis Colon Rectum 1989;32(5):40916.
[12] Anderson JR, Mills JO. Caecal volvulus: a frequently missed diagnosis? Clin Radiol 1984;35(1):65-9.

[13] Moore CJ, Corl FM, Fishman EK. CT of cecal volvulus: unraveling the image. Am J Roentgenol 2001;177(1):95-8.

[14] Majeski J. Operative therapy for cecal volvulus combining resection with colopexy. Am J Surg 2005;189(2):211-3. 